\title{
Cultural Self-Views Influence Meaning Making: Self-Construals as Differential Predictors of Meaning in Life among Filipino University Students*
}

\section{Las autoestimaciones culturales influyen en la construcción del significado: las autoconstrucciónes como predictores diferenciales del significado de vida de estudiantes universitarios filipinos}

Received: 25 April 2016 | Accepted: 01 June 2018

\author{
Jesus Alfonso Daep Datu ${ }^{\mathrm{a}}$ \\ The Education University of Hong Kong, China \\ ORCID: http://orcid.org/0000-0002-8790-1113 \\ Maria Guadalupe Salanga \\ De La Salle University, Filipinas \\ ORCID: http://orcid.org/0000-0001-9752-7594
}

a Correspondence author: E-mail: jadatu@eduhk.hk

How to cite: Datu, J. A. D., \& Salanga, M. G. (2018). Cultural self-views influence meaning making: Selfconstruals as differential predictors of meaning in life among Filipino university students. Universitas Psychologica, 17(5), 1-9. https://doi.org/10.11144/Ja veriana.upsy17-5.csvi

\begin{abstract}
Meaning in life refers to the extent to which individuals realize the meaning of their lives (presence of meaning) and are eager to understand the meaning of their existence (search for meaning). Whereas previous research has shown that meaning in life was associated with a wide range of positive psychological outcomes, few investigations explored the social and contextual correlates of a meaningful life. The present study addressed this gap by examining the degree to which self-construal (independent and interdependent self-construals) was differentially related to meaning in life dimensions among Filipino university students. Findings of the structural equation modeling showed that independent self-construal was positively associated with the presence of meaning while interdependent self-construal was positively linked to search for meaning. The theoretical and practical implications are discussed.
\end{abstract}

Keywords

Filipino university students; meaning in life; self-construal.

\section{RESUMEN}

El significado en la vida se refiere a la medida en que los individuos dan cuenta del significado de sus vidas (presencia de significado) y están ansiosos por comprender el significado de su existencia (búsqueda de significado). Mientras que la investigación previa ha demostrado que el significado en la vida se asocia con una amplia gama de resultados psicológicos positivos, pocas investigaciones han explorado los correlatos sociales y contextuales de una vida significativa. El presente estudio abordó esta brecha mediante el examen del grado en que la autoconstrucción (autoconstrucción independiente e interdependiente) se relaciona de manera diferencial con el significado en las dimensiones de la vida entre los estudiantes universitarios filipinos. Los resultados del modelo de ecuaciones estructurales mostraron que la autoconstrucción independiente se asocia positivamente con la presencia 
de significado, mientras que la autoconstrucción interdependiente se relaciona positivamente con la búsqueda de significado. Se discuten las implicaciones teóricas y prácticas.

Palabras clave

estudiantes universitarios filipinos; significado en la vida; autoconstrucción.

Psychological scientists have long recognized the power of meaning in life in cultivating optimal human functioning (Donaldson, Dollwet, \& Rao, 2015). Meaning in life is regarded as an essential construct in its own right given its critical consequences on a wide range of psychological outcomes. Steger, Frazier, Oishi, and Kaler (2006) define meaning in life as the extent to which individuals sense the meaning of their lives. It is composed of two key dimensions: the presence of meaning (the realization that life is essential and purposeful) and the search for meaning (motivation to find life's meaning).

Previous research demonstrates that meaning in life may catalyze well-being and psychological health. Meaning in life is associated with higher psychological well-being (Brassai, Piko, \& Steger, 2012; Krok, 2015), life satisfaction (Datu \& Mateo, 2015; Steger et al., 2008), self-esteem (Steger et al., 2006), school adjustment (Kiang $\&$ Witkow, 2015), and physical health (Brassai et al., 2012, 2015). People who possess greater meaning in life are less likely to report of depression (Steger et al., 2006), anxiety (Miller $\&$ Rottinghaus, 2014), negative emotions (Kiang \& Witkow, 2015), suicidal ideation (Henry et al., 2014), and career indecision (Miller \& Rottinghaus, 2014).

Alternatively, some investigations have paid attention to the predictors of meaning in life. Among the identified antecedents of meaning in life involve career adaptability (Yuen \& Yau, 2015), gratitude (Datu \& Mateo, 2015; Kleiman, Adams, Kashdan, \& Riskind, 2013), emotional clarity (Abeyta, Routledge, Juhl, \& Robinson, 2015), self-efficacy (Brassai, Piko, \& Steger, 2013), and positive affect (Datu, 2016; Hicks \& King, 2007). While these studies have examined person-related predictors of a meaningful life, it seems that limited research explored social, contextual, and cultural variables which may influence meaning in life.

Therefore, the primary aim of the study was to assess the associations of cultural self-views (self-construal) with meaning in life domains. Particularly, our research expanded the study of Steger, Kawabata, Shimai, and Otake (2008) who found that Americans who are embedded in an individualist culture scored higher presence of meaning while Japanese who are entrenched in a collectivist context had greater search for meaning. As Steger and his colleagues (2008) express the need to investigate the role of culture-bound self-views (independent and interdependent self-concepts) on life meaning, our study evaluated the extent to which interdependent and independent self-construal may be differentially associated with the presence of and search for meaning in life.

\section{Self-construal theory}

The self-construal theory (Markus \& Kitayama, 1991) postulates the basic cultural self-views explain cultural differences in feelings, thoughts, and behaviors. There are two dimensions of cultural self-views namely: independent and interdependent self-construals. Independent self-construal is a view of self which is more common for people in the Western and individualist cultures. People who engender this self-construal tend to place higher value in taking actions that reflect their dispositions and values. Interdependent self-construal, on the other hand, is a view of self which is more typical for individuals who are embedded in the non-Western collectivist settings. For individuals who espouse an interdependent construal of self, most of the actions or behaviors are predicated on forming and maintaining sound relationships with others. Markus and Kitayama (1991) have also noted that it is possible for both selfconstruals to exist within a specific context. 
Social and contextual correlates of meaning in life

Previous research has identified some social and contextual predictors of meaning in life which may include, but were not limited to, attachment orientations (Lopez, Ramos, Nisenbaum, Thind \& Ortiz-Rodriguez, 2015), connectedness to nature (Howell, Passmore, \& Buro, 2013), maternal responsiveness (Brassai et al., 2013), social interests (Kim, Park, \& Hogge, 2015), and sense of belongingness (Lambert et al., 2013). Avoidance and anxiety attachment orientations had stronger negative correlations with the presence of meaning than search for meaning in life (Lopez et al., 2015). Previous studies have not paid much attention to cultural correlates of a meaningful life.

\section{Theoretical perspective}

There are several lines of evidence which points to the likelihood that different extent of selfconstrual may have similar associations with perceptions of meaning in life. First, Steger et al. (2008) have found that individuals who endorse independent self-construals tend to show more significant presence of meaning than those endorse interdependent self-construals. Those with more interdependent views of the self also display a greater search for meaning in life. Second, the study of Datu (2016) has revealed that in a collectivist context, individuals' inclination to search for the most optimal choice in life was associated with the higher presence of meaning in life. Third, people in individualist cultures are more inclined to foster a more positive selfimage (self-enhancement) compared to those in collectivist societies who are prone to criticize and improve self-image (self-effacement) (Heine, Lehman, Markus, \& Kitayama, 1999). Fourth, prior evidence about cultural differences in cognitive styles has shown that those who are entrenched in individualist cultures tend to use an analytic thinking style while individuals who are embedded in collectivist societies tend to adopt a dialectical thinking style (Nisbett, Peng,
Choi, \& Norenzayan, 2001; Peng \& Nisbett, 1999). As a consequence of enjoying a dialectical way of thinking, collectivists appreciate the importance of dealing with contradictory and divergent perspectives. These lines of evidence would likely suggest that an interdependent self-view (interdependent self-construal) may be strongly associated with the search for meaning while an independent self-construal may be strongly linked to the presence of meaning in life.

\section{The current study}

The study aimed to examine the associations of cultural self-views with meaning in life dimensions through a structural equation modeling approach. Specifically, we investigated the extent to which independent and interdependent self-construals may be associated with the presence of and search for meaning in life among a Filipino university student sample. Our study offered two contributions to the extant meaning in life literature.

First, whereas past literature has explored the social antecedents of a meaningful life (e.g., Howell et al., 2013; Lambert et al., 2013; Lopez et al., 2015), it appears that no study assessed the linkage between cultural variables and meaning in life. Our research hopes to fill this research gap through investigating self-construal dimensions as differential predictors of meaning in life. Although Steger et al. (2008) found that crosscultural distinctions existed on meaning in life among the U.S. and Japanese contexts, they did not examine the role of specific cultural variables in experiencing a meaningful life. To our knowledge, this is the first study which explored the association of self-construals with meaning in life.

Second, while previous studies have assessed meaning in life in the Western cultural contexts, limited studies were conducted in collectivist societies such as Turkey, Philippines, Japan, and Hong Kong (i.e., Boyraz, Lightsey, \& Can, 2013; Datu, 2016; Steger et al., 2008; Yuen $\&$ Yau, 2015). In that sense, our study can offer promising insights regarding the potential 
cross-cultural applicability of the meaning in life construct in the Philippines which is also considered as a collectivist context (Datu, 2015).

The following hypotheses were tested in our study:

H1: Independent self-construal will positively predict the presence of meaning.

$\mathrm{H} 2$ : Interdependent self-construal will positively predict the search for meaning.

\section{Method}

\section{Participants}

The sample was comprised of 156 Filipino undergraduate students from a private university in Metro Manila. The average age of the participants was 17.68 a standard deviation of 2.87. There were 62 male and 91 female students while 3 participants failed to specify gender in the demographic detail form. The participants were requested to fill up consent forms before taking part in the present research.

\section{Instruments}

\section{Self-construal}

The revised version of the Self-Construal Scale (Hashimoto \& Yamagishi, 2013) was used to measure independent and interdependent selfconstruals in the study. The items were rated on a 7 -point Likert scale $(1=$ Does not describe at all; $7=$ Describes very well). Sample items in the scale are: "I always express my opinions clearly" and "I like being unique and different from others in many respects" (independent selfconstrual); "I find myself being concerned about what other people think of me" and "I feel good when I cooperate with others" (interdependent self-construal).

\section{Meaning in life}

The Meaning in Life Scale (Steger et al., 2006) measured the extent to which the participants endorse the presence of and search for meaning in life. The items were marked on a 7 -point Likert scale ( $1=$ Absolutely untrue; $7=$ Absolutely true). Here are sample items in the scale: "I understand my life's meaning" and "My life has a clear sense of purpose" (presence of meaning); "I am looking for something that makes my life feel meaningful" and "I am always looking to find my life's purpose" (search for meaning).

\section{Data analysis}

Several statistical analyses were conducted to test the hypotheses of the study. The mean, standard deviation, and Cronbach's alpha reliability coefficients of the constructs were computed. Pearson-r correlational analyses were also performed to assess the association among the variables (i.e., independent self-construal, interdependent self-construal, presence of and search for meaning in life). Calculation of descriptive statistics and correlational analyses was carried out using the 23rd version of the Statistical Package for the Social Sciences.

We also followed the two-step approach of Anderson and Gerbing (1988) which involved testing a measurement model to examine the extent to which the latent constructs are represented by its corresponding indicators (Step 1) and a structural model to evaluate the associations of each self-construal type with meaning in life dimensions (Step 2). In Step 1 , three parcel indicators were created for each type of self-construal while two parcel indicators were formed for each meaning in life domain because Little, Cunningham, Shahar, and Widaman. (2002) suggested the use of parceling for latent constructs with numerous indicators to produce more accurate parameter estimates of the hypothesized measurement and structural model. To assess the fit of both models, we referred to the some of the criteria set Marsh 
et al. (2010) which stipulated that a good-fitting model should have the following range of values: a.) Goodness of Fit Index (GFI), Comparative Fit Index (CFI), and Incremental Fit Index (NFI) with values that are greater than .95; and b.) Root Mean Square Error of Approximation (RMSEA) should be lower than .08.

\section{Results}

\section{Preliminary analysis}

The results of descriptive statistics and correlational analyses are shown in Table 1 . The pattern of association was consistent with the hypotheses posited in the study. Particularly, independent self-construal was positively correlated with the presence of meaning while interdependent self-construal was positively correlated with the search for meaning (See Table 1).

\section{Table 1}

Descriptive statistics, reliability, and correlational coefficients among the variables

\begin{tabular}{lccccccr}
\hline \multicolumn{1}{c}{ Variable } & $\alpha$ & $M$ & $S D$ & \multicolumn{4}{c}{$r$} \\
\cline { 5 - 9 } & & & & 1 & 2 & 3 & 4 \\
\hline 1. Independent self-construal & 0.74 & 4.81 & 0.78 & - & & \\
2. Interdependent self-construal & 0.70 & 4.99 & 0.68 & $0.10^{*}$ & - & \\
3. Presence of meaning & 0.80 & 5.14 & 1.08 & $0.24^{* *}$ & -0.10 & - & \\
4. Search for meaning & 0.84 & 5.29 & 1.07 & 0.01 & $0.25^{* *}$ & $0.45^{* *}$ & - \\
\hline & $* \mathrm{p}<0.05, * *$ & $\mathrm{p}<0.01$ & &
\end{tabular}

\section{Measurement model}

The hypothesized measurement model was composed of four latent constructs with the following number of indicators: independent self-construal (3 parcels), interdependent selfconstrual (3 parcels), presence of meaning (2 parcels), and search for meaning (2 parcels). Results of confirmatory factor analysis showed a very good fitting model: $\chi^{2}=42.64, d f=$ 29, $p<0.05$, CFI $=0.96$, GFI $=0.96$, IFI $=0.96$, and RMSEA $=0.05$ (C.I. $90 \%=$ 0.003-0.088). All indicators significantly loaded on the hypothesized latent constructs.

\section{Structural equation model}

The hypothesized structural model had excellent fit: $\chi^{2}=42.64, \mathrm{df}=29, p<0.05, \mathrm{CFI}=0.96$, $\mathrm{GFI}=0.95$, IFI $=0.96$, and RMSEA $=0.05$ (C.I. $90 \%=0.003-0.088$ ) (Refer to Figure 1). $\mathrm{H} 1$ was supported as independent self-construal positively predicted presence of meaning in life. Confirming $\mathrm{H} 2$, interdependent self-construal positively predicted search for meaning in life.

\section{Figure 1}

Final structural model on the link between selfconstrual and meaning in life dimensions

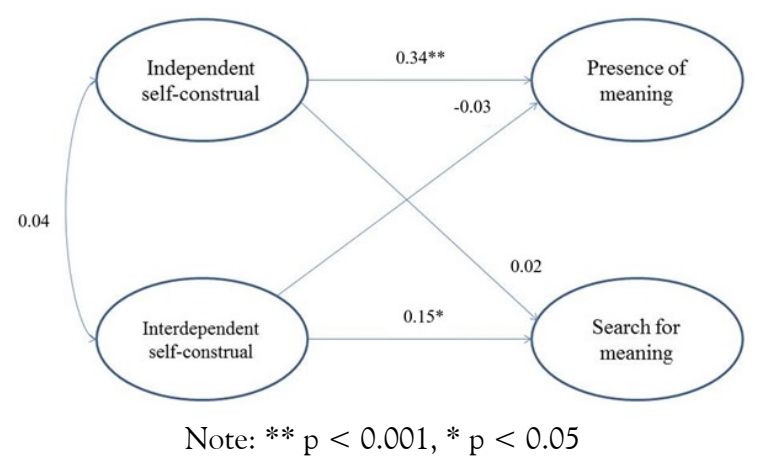

\section{Discussion}

The study examined the associations of selfconstrual with meaning in life dimensions. Findings converged with our hypotheses regarding the differential association of independent and interdependent self-construals to the presence of and the search for life's meaning.

Our findings confirm our first two hypotheses. The endorsement of an independent selfconstrual is associated with higher perceptions of meaning in life (H1). This implies that individuals who tend to see their selves as an autonomous and separate entity in a broader social context are likely to realize the purpose of their existence. Alternatively, interdependent self-construal is linked to the higher search for meaning $(\mathrm{H} 2)$. This suggests that individuals who embody a socially-oriented self-view are more inclined to engage in activities which may lead to a meaningful life. 
Our findings indicate that basic cultural selfviews may influence perceptions of meaning in life. A potential explanation for this can be offered by the self-construal theory (Markus \& Kitayama, 1991) which posits that different types of self-construal may have significant consequences to various psychological processes. As the model suggests that independent view of self can result to desirable outcomes such as self-actualization and realizing one's self (Markus \& Kitayama, 1991), it is likely that those who with higher endorsement ratings for independent self-construal may realize the significance of their lives. Individuals with this self-construal that emphasize the uniqueness of the self, the importance of self-expression, and promoting one's own goals. All these features may contribute to the experience of attaining meaning in life. However, meaning in life is different for those with a tendency to view the self as an interdependent entity. These individuals emphasize developing harmonious relationships, fulfilling roles, and adjusting to the broader social and contextual conditions (Markus \& Kitayama, 1991; Suh, 2007). The construction of the self as a malleable and fluid entity may prompt the individual to continually search for meaning, looking to various roles and contexts as opportunities to find a sense of purpose. Therefore, it is probable that individuals with an interdependent self-view may realize the significance of finding ways to search for life's meaning.

Our investigation has some limitations. Given the correlational design of our study, causal conclusions may not be drawn from the present findings. Future investigations can address this through the use of longitudinal designs to assess temporal precedence between self-construal and meaning in life dimensions in greater detail. Causal inferences regarding cultural self-views and meaning in life can be tested through experimental designs. Further, as the study solely relied on self-report data, the results may be prone to common method bias. This methodological gap can be filled in future studies via theuse of alternative approaches (e.g., peerreport) in assessing both self-construal and meaning in life. The relatively small sample size also serves as one limitation in the present study which can be addressed by using a larger sample size in future research. Moreover, future investigations can examine complex theoretical mechanisms on how self-construal may differentially predict life's meaning.

Despite the methodological limitations, our study offers promising theoretical and practical implications. Regarding theory, our research distinctly contributes to the extant meaning in life literature as we demonstrate that different self-construal may be associated with distinct meaning in life dimensions. Our findings suggest that cultural self-views plays a vital role in cultivating presence of and search for meaning in life especially in a collectivist context. To the best of our knowledge, it seems that our study provides preliminary evidence on the potential theoretical linkage of self-construal to meaning in life. As regards to practice, the study suggests that it may be a critical direction for psychologists, counselors, and mental health workers to assess the cultural selfviews of individuals in the conceptualization and implementation of meaning in life interventions.

\section{Compliance with Ethical Standards}

Conflict of interest: There is no conflict of interest in the present study as the authors did not receive funds from any institution. Ethical approval: All procedures performed in studies involving human participants were by the ethical standards of the institutional and national research committee or comparable ethical standards. Informed consent was also obtained from all individual participants included in the research. This article does not contain any studies with animals performed by any of the authors.

\section{References}

Abeyta, A. A., Routledge, C., Juhl,
J., \& Robinson, M. D. (2015).
Finding meaning through emotional | Universitas Psychologica | V. I7 | No.5 | 2018 | 
understanding: emotional clarity predicts meaning in life and adjustment to existential threat. Motivation and Emotion, 39(6), 973-983. http://dx.doi.org/10.1007/s 11031-015-9500-3

Anderson, J. C., \& Gerbing, D. W. (1988). Structural equation modeling in practice: A review and recommended two-step approach. Psychological Bulletin, 103(3), 411-423.

Boyraz, G., Lightsey Jr., O. R., \& Can, A. (2013) The Turkish version of the meaning in life questionnaire: Assessing the measurement invariance across Turkish and American adult samples, Journal of Personality Assessment, 95 (4), 423-431. http://dx.doi.o $\mathrm{rg} / 10.1080 / 00223891.2013 .765882$

Brassai, L., Piko, B. F., \& Steger, M. F. (2012). Existential attitudes and Eastern European adolescents' problem and health behaviors: Highlighting the role of search for meaning in life. The Psychological Record, 62, 719-734. Retrieved from http://www.michaelfsteger.com/wp-c ontent/uploads/2012/12/Brassai-Piko-Steg er-TPR-2012.pdf

Brassai, L., Piko, B. F., \& Steger, M. F. (2013). Individual and parental factors related to meaning in life among Hungarian minority adolescents from Romania. International Journal of Psychology, 48(3), 308-315. http://dx.doi.org/10.1080/ 00207594.2011 .645483

Brassai, L., Piko, B. F., \& Steger, M. F. (2015). A reason to stay healthy: The role of meaning in life in relation to physical activity and healthy eating outcomes among adolescents. Journal of Health Psychology, 20(5), 473-482. https:// doi.org/10.1177/1359105315576604

Datu, J. A. D. (2015). Validating the revised self-construal scale in the Philippines. Current Psychology: A Journal for Diverse Perspectives on Diverse Psychological Issues, 34(4), 626-633. http://dx.doi.org/10.1007/s 12144-014-9275-9

Datu, J. A. D. (2016). The synergistic interplay between positive emotions and maximization enhances meaning in life: A study in a collectivist context. Current Psychology: A Journal for Diverse Perspectives on Diverse Psychological Issues, 35(3), 459-466. http://dx.doi.org/10.1007/s12144 $-015-9314-1$

Datu, J. A. D., \& Mateo, N. J. (2015). Gratitude and life satisfaction among Filipino adolescents: The mediating role of meaning in life. International Journal for the Advancement of Counseling, 37(2), 198-206. http://dx.doi.org/10.1007/s10447 $-015-9238-3$

Donaldson, S. I., Dollwet, M., \& Rao, M. A. (2015). Happiness, excellence, and optimal human functioning revisited: Examining the peer-reviewed literature linked to positive psychology. The Journal of Positive Psychology, 10(3), 185-195. https://doi.org/ 10.1080/17439760.2014.943801

Hashimoto, H. \& Yamagishi, T. (2013). Two faces of interdependence: Harmony seeking and rejection avoidance. Asian Journal of Social Psychology, 16(2), 142-151. https://doi.org/ 10.1111/ajsp.12022

Heine, S. J., Lehman, D. R., Markus, H. R., \& Kitayama, S. (1999). Is there a universal need for positive self-regard? Psychological Review, 106(4), 766-794. Retrieved from https://www.ncbi.nlm.nih.g ov/pubmed/10560328

Henry, K. L., Lovegrove, P. J., Steger, M. F., Chen, P. Y., Cigularov, K. P., \& Tomazic, R. G. (2014). The potential role of meaning in life in the relationship between bullying victimization and suicidal ideation. Journal of Youth and Adolescence, 43, 221-232. http s://doi.org/10.1007/s10964-013-9960-2

Hicks, J. A., \& King, L. A. (2007). Meaning in life and seeing the big picture: Positive affect and global focus. Cognition and Emotion, 21 (7), 1577-1584. https://doi.org/10.1080/ 02699930701347304

Howell, A. J., Passmore, H. A., \& Buro, K. (2013). Meaning in nature: Meaning in life as a mediator of the relationship between nature connectedness and wellbeing. Journal of Happiness Studies, 14, 
1681-1696. https://doi.org/10.1007/s10902 $-012-9403-x$

Kiang, L., \& Witkow, M. R. (2015). Normative changes in meaning in life and links to adjustment in adolescents from Asian American backgrounds. Asian American Journal of Psychology, 6(2), 164-173. http:// dx.doi.org/10.1037/aap0000018

Kim, E., Park, H. J., \& Hogge, I. (2015). Examination of the Adlerian constructs of activity and social interest with depression among recent Korean retirees: Meaning in life as a mediator. Archives of Gerontology and Geriatrics, 61 (3), 378-383. http://dx.do i.org/10.1016/j.archger.2015.07.003

Kleiman, E. M., Adams, L. M., Kashdan, T. B., \& Riskind, J. H. (2013). Gratitude and grit indirectly reduce risk of suicidal ideations by enhancing meaning in life: Evidence for a mediated moderation model. Journal of Research in Personality, 47, 539-546. http://d x.doi.org/10.1016/j.jrp.2013.04.007

Krok, D. (2015). The role of meaning in life within the relations of religious coping and psychological well-being. Journal of Religious Health, 54(6), 2292-2308. http://dx.doi.org /10.1007/s10943-014-9983-3

Lambert, N. M., Stillman, T. F., Hicks, J. A., Kamble, S., Baumeister, R. F., \& Fincham, F. D. (2013). To belong is to matter: Sense of belonging enhances meaning in life. Personality and Social Psychology Bulletin, 39, 1418-1427. http://dx.doi.org/10.1177/0146 167213499186

Little, T. D., Cunningham, W. A., Shahar, G., \& Widaman, K. F. (2002). To parcel or not to parcel: Exploring the question weighing the merits. Structural Equation Modeling, 9(2), 151-173. Retrieved from http://faculty.psy.ohio-state.edu/cunn ingham/pdf/little.sem.2002.pdf

Lopez, F. G., Ramos, K., Nisenbaum, M., Thind, N., \& Ortiz-Rodriguez, T. (2015). Predicting the presence and search for life meaning: Attachment theory-drive model. Journal of Happiness Studies, 16(1), 103-116. Retrieved from https://link.springer.com/ar ticle/10.1007/s10902-013-9498-8
Markus, H. R., \& Kitayama, S. (1991). Culture and the self: Implications for cognition, emotion, and motivation. Psychological Review, 98(2), 224-253. http://doi.org/10.1 037/0033-295X.98.2.224

Marsh, H. W., Lüdtke, O., Muthén, B., Asparouhov, T., Morin, A. J. S., Trautwein, U., \& Nagengast, B. (2010). A new look at the big five factor structure through exploratory structural equation modeling. Psychological Assessment, 22(3), 471-491. ht tp://dx.doi.org/10.1037/a0019227

Miller, A. D., \& Rottinghaus, P. J. (2014). Career indecision, meaning in life, and anxiety: An existential framework. Journal of Career Assessment, 22(2), 233-247. https://doi.org/ 10.1177/1069072713493763

Nisbett, R. E., Peng, K., Choi, I., \& Norenzayan, A. (2001). Culture and systems of thought: holistic versus analytic cognition. Psychological Review, 108(2), 291-310. Retrieved from https://www.ncbi. nlm.nih.gov/pubmed/11381831

Peng, K., \& Nisbett, R. (1999). Culture, dialectics, and reasoning about contradiction. American Psychologist, 54(9), 741-754. Retrieved from https://culcog.ber keley.edu/Publications/1999AmPsy_DT.p df

Steger, M. F., Frazier, P., Oishi, S., \& Kaler, M. (2006). The meaning in life questionnaire: assessing the presence of and search for meaning in life. Journal of Counseling Psychology, 53(1), 80-93. https://doi.org/10. 1037/0022-0167.53.1.80

Steger, M. F., Kawabata, Y., Shimai, S., \& Otake, K. (2008). The meaningful life in Japan and the United States: levels and correlates of meaning in life. Journal of Research in Personality, 42, 660-678. https://doi.org/10. 1016/j.jrp.2007.09.003

Suh, E. M. (2007). Downsides of an overly context-sensitive self: Implications from the culture and subjective wellbeing research. Journal of Personality, 75(6), 1331-1343.https://doi.org/10.1111/j. 1467-6494.2007.00477.x 
Yuen, M., \& Yau, J. (2015). Relation of career adaptability to meaning in life and connectedness among adolescents in Hong Kong. Journal of Vocational Behavior, 91, 147-156. http://dx.doi.org/10.1016/j.jvb.20 15.10 .003

\section{Notes}

* Research article. 